\title{
Theory of Systems, Systems Metaphysics and Neoplatonism
}

\author{
J.L. Usó-Doménech ${ }^{1, *}$, J.A. Nescolarde-Selva ${ }^{1}$, M.J. Sabán ${ }^{2}$ \\ ${ }^{1}$ Department of Applied Mathematics. University of Alicante. Alicante. Spain. \\ ${ }^{2}$ Department of Philosophy. University Rey Juan Carlos. Madrid. Spain \\ *Corresponding author: josue.selva@ua.es
}

Received March 31, 2015; Revised April 05, 2015; Accepted April 14, 2015

\begin{abstract}
Science has been developed from the rational-empirical methods, having as a consequence, the representation of existing phenomena without understanding the root causes. The question which currently has is the sense of the being, and in a simplified way, one can say that the dogmatic religion lead to misinterpretations, the empirical sciences contain the exact rational representations of phenomena. Thus, Science has been able to get rid of the dogmatic religion. The project for the sciences of being looks to return to reality its essential foundations; under the plan of theory of systems necessarily involves a search for the meaning of Reality.
\end{abstract}

Keywords: being, essence, existence, form, Ibn Gabirol, Isaac Luria, Kabbalah, Neoplatonism, substance, system, theodicy

Cite This Article: J.L. Usó-Doménech, J.A. Nescolarde-Selva, and M.J. Sabán, "Theory of Systems, Systems Metaphysics and Neoplatonism.” American Journal of Systems and Software, vol. 3, no. 2 (2015): 36-43. doi: 10.12691/ajss-3-2-2.

\section{Introduction}

Science raises numerous questions, and generally, the sense of reality does not arise from the representation. Moreover, from certain rational representations, there are paradoxes and without senses, while a category of phenomena arises from scientific framework linked to the postulate of objectivity. Since its inception in the 1930s by Ludwig von Bertalanffy, systems theory has been associated with biology, cybernetics, chaos theory, nonlinear dynamics, psychology, and cognitive science. From a systems-theory perspective, the mind is an interdependent network of factors and processes that function to constrain awareness and to maintain itself in the face of stresses and perturbations, creating a steady state of consciousness. Duality is an essential feature of this state, particularly as manifested in the sense of the self as distinct from the world and in evaluative associations, such as the good or the repellent. But this seemingly steady state of ordinary consciousness itself depends on interrelated variables that constitute it: an internal narrative, attentional orientation, defense mechanisms, for example, repression and projection, and distractionseeking behavior. These factors and processes are interdependent and mutually reinforcing, and together function to both construct and defend a dualistic state of consciousness. As a consequence, ordinary experience, which we generally take to be the most solid and reliable, is actually a construction, what we take to be real or substantial is in fact the result of a complex, interwoven system that constitutes itself to function in an effective manner. The steady state of consciousness is inherently a conservative system designed to fend off disturbances and to this extent, everyday reality necessarily retreats from deeper layers of experience. These modes of representation are not answers, but the means of questioning concerning the understanding of the describable properties from a systemic perspective.

Modern science, especially physics, has continued on the trajectory established by Newton and is becoming more Pythagorean. Since long before the arrival of string theory, however, the scientific perspective has been that the true structure of reality is very different from our sensory experience of it. Famously, the eminent physicist John Archibald Wheeler (1994) proposed the ontological maxim "it from bit" to express the idea that all the fundamental laws of physics are formal information relationships; there is no "stuff" that they are about, or to put it differently, the apparent stuff (such as strings, wawefunctions, fields, and particles) is constituted entirely by formal mathematical relationships. "Everything is number," indeed. Another example of Pythagoreanism in contemporary science is complex systems theory, which attempts to find mathematical laws of emergence and selforganization throughout nature. The same laws are found to operate at many different levels, from atoms, to neurons, to embryological development, to social behavior and communication, to evolution, both cosmic and terrestrial. These are laws dealing with the dynamics of opposites: expansion and contraction, cooperation and competition, uniformity and diversity, randomness and order, definiteness and indefiniteness, discreteness and continuity, and so forth. That is, Pythagorean ideas of unity, duality, conjunction and mediation, balance and 
equilibrium, and so forth, are found to be the fundamental principles at all levels of the cosmos and so the structure of these Pythagorean archetypes is the structure of the universe, at least insofar as we can understand it. We do not claim that developments in complex systems theory were motivated in any direct way by Pythagorean or Neoplatonic philosophy. Our point is that complex systems theory is Pythagorean in spirit, in that processes throughout nature are governed by a few fundamental mathematical archetypes, such as we find in Pythagorean philosophy.

While many of the principle features of Lurianic Kabbalah can be traced to earlier sources, it is the openended evolution of the older characters and the drama of their interrelationships that finds an unprecedented level of high definition and complexity. The system, familiar on a general scale, invites one to encounter uncharted territory in the unexpected twists of phenomena mirrored back onto them with a new degree of detail. Unpacking the particulars of the multi-tiered edifices requires additional conceptual scaffolding in order to mount the challenge from the outside. There is a notion of a "complex systems theory" within Jewish mystical literature. Particular to the corpus of Lurianic writing, this newfound complexity may best be described with the aid of far reaching tools of philosophy, mathematics and physics. Courted for comparison are the theories of the fold and monad in Leibniz, Mandelbrot's fractals and Bohm's holographic universe and implicate order. For Elliot Wolfson (1998) the Lurianic Kabbalah is an "antisystem" or the "system whose complexity drives it beyond its own usefulness as a system rendering it effectively the system of the non-system."

The systems view privileges form and process over substance, wholes over parts, and emergence over reduction. It accords ontological status to systems at all scales, to function as well as structure, and to the possible as well as the actual. There are also other compatibilities and links between systems ideas and the religious traditions. Systems theory models gradations of purposefulness. It sees planetary life as a self-regulating whole that arises from and has significance in a cosmological context. The "edge of chaos" idea allows one to model the union of order and creativity in nature. Boulding's hierarchy of systems types (1956, pp. 3-10.) is in effect a scientific reformulation of the "great chain of being” (Lovejoy, 1936). The triad of matter, energy, and information echoes the three gunas of the Samkhya tradition of India. The noosphere of Teilhard (1959) exists in rudimentary form in the Internet, and the distance between certain conceptualizations of 'angel' and the idea of 'meme' is not so great. Numerous other religious ideas have systems-theoretic cognates. Systems metaphysics could be central to a new world view that has extensive and subtle religious implications.

\section{The Essence-Existence Dialectics}

In according to western metaphisical tradition we start from two a priori hypothesis (Nescolarde-Selva and UsóDoménech, 2014, Nescolarde-Selva, Usó-Doménech and Gash, 2014; Nescolarde-Selva, Usó-Doménech and Sabán, 2015):
1) We assume the existence of an Absolute Reality, unattainable by human knowledge that is not fragmented into parts. This Absolute Reality we denote as $\aleph$.

2) We suppose also that there is a relative reality, achievable by human knowledge, which is fragmented into parts. This relative reality is denoted as $ב$ and will be considered by the subject $S$ as the only Reality.

Let $\mathrm{K}$ be the operator of knowledge that is part of the subject S. Subject $S$ is conceiving Reality $ב$ through his doxical filter made up of the own beliefs system B of his culture, and by a certain language $\mathrm{L}$. Subject $\mathrm{S}$ is in a certain psychic state of organization of Reality during a determined objective temporary interval $\left[t_{0}, t_{n}\right]$. Then:

Hypothesis 1: $\aleph \Rightarrow \exists \beth \backslash S \in \beth . \neg K \aleph(\aleph \Rightarrow \exists \beth)$ and $\mathrm{K} \beth(\Rightarrow) \mathrm{K}$ א

$$
\text { Hypothesis 2: } \beth<\boldsymbol{N}, \beth=\sum_{i=1}^{n} \beth_{\mathrm{i}} \text { such that } \beth>\sum_{i=1}^{n} \beth_{\mathrm{i}}{ }^{1}
$$

When we speak of an organized and natural system we are referring to systems within that fragmented and relative reality.

We propose the following five principles:

Metaphysical Principle 1: Relative reality has two phases: an exoteric and the other esoteric, such that if we consider a being, the exoteric part corresponds to existing being, and the esoteric part is the essence ${ }^{2}$ of the being.

1 LeShan and Margenau (1982) propose that the organization of knowledge divides Reality in domains of experience and in each one of them certain observable phenomena are expressed. Some domains have a direct relation with each other and when this happens it is possible to make a series of formulations defined by their relations. When the domains are interrelated according to scales of dimensions of complexity usually we can say that they form a hierarchy. In these conditions, the observable phenomena in one domain cannot be conceived nor be predicted generally from another domain. But if two domains are considered to be in opposed directions, we can verify that the observable phenomena in the second domain can be explained taking care of the phenomena of the first domain. According to these authors, an important general law concerning domains is as follows: the observable phenomena that appear in any domain legitimately are interrelated. In accordance with the present state of knowledge and science, no domain of experience is more real than another one. Each one has the same worth as another one. "Nature has neither rind nor bone", said Goethe. We chose a domain according to our purposes. Even though the domains are related in a hierarchy none of them is more real than the other. The domains enter groupings called spheres and each sphere has one special organization of Reality (its Metaphysical system) that is necessary so that the data of that sphere are valid. LeShan and Margenau define five spheres of experience (Nescolarde-Selva and Usó-Doménech, 2014): a) Sphere of things too small to be seen or touched at least theoretically: the Microcosm. It is the field of Quantum Mechanics. b) Sphere of the tactile line of vision and up to the limits of instrumentation. It could be called also the sensory sphere or average existence. c) Sphere of very large objects or things that theoretically happen too fast to be seen or to be touched: Macrocosms. It is the field of relativistic Physics. D) Units of conduct with sensory feedback: conduct units that depend on reflections. E) Sphere of inner human experience, including bodily sensations. 2 Essence is properly described as that whereby a thing is what it is, an equivalent of the to ti en einai of Aristotle (Metaph., VII, 7). The essence is thus the radical or ground from which the various properties of a thing emanate and to which they are necessarily referred. Thus the notion of the essence is seen to be the abstract counterpart of the concrete entity; the latter signifying that which is or may be (ens actu, ens potentiâ), while the former points to the reason or ground why it is precisely what it is. As furnishing in this manner an answer to the question What? (Quid?) — as, e.g., What is man? — essence is equivalent to quiddity; and thus, as Aquinas remarks (I, Q. iii, a. 3), the essence of a thing is that which is expressed by its definition. The characteristic attributes of the essence are immutability, indivisibility, necessity and infinity. 
Overemphasizing history is often associated with the denial of 'essences,' i.e., with the nominalist as opposed to the realist philosophical position. If 'essence' means something fixed and unitary, then historicity and multiplicity do indeed imply that there are no essences. But if essence just means deep as opposed to surface structure, then diachronic change and heterogeneity do not invalidate the idea of essence. A species genotype is an essence. Species evolve, yes; they are instantiated in actual populations, yes; but within-species and temporal genomic variation do not negate the fact of betweenspecies variation. Essences can be fuzzy rather than crisp (and fuzzy sets and relations are important components of systems theory). Structure is the residue of history. When structure is differentiated into a relatively fixed homogeneous core and a relatively variable heterogeneous periphery, when this core supplies the algorithmic information for the whole structure, one can legitimately speak of essence. Arguments against essences are ideological, not scientific.

The command of the facts is relative to existing being; thus, the representation of these events also corresponds to existing being. If we consider a complex system, it is observed and then represented. This representation describes the organized existence, ie, the spatiotemporal organization of the different components and their transformations in the system. Current theories described in this way to existing being, while the being-by-essence is not included in this type of representation.

Metaphysical Principle 2: The concept of being is described as a dynamic dualism essence-existence.

The intelligible-sensitive, form-matter, spirit-matter dualisms, should be abandoned in favor of an essenceexistence dualism. If this view is accepted, it is necessary that the existing being not be separated from the beingfor-essence. So this dualism will be dynamic. This dynamic imposes the introduction of two motions:

1) A movement from the essence to existence.

2) A movement from existence to essence.

Thus we find the idea of two connected dialectic described by Hegel (1969); these could be stated as a pulse, ie, as a sequence of systole and diastole, as Schelling says (2000). Existence is not an accident of essence, but approaches their essence by this double movement.

Metaphysical Principle 3: The essence-existence dualism states according to a neohylomorphic ${ }^{3}$ conception according to which relative reality is made on form and motion.

Neohylomorphic conception approaches to substantialist Aristotelian conception ${ }^{4}$. However, if we

3 The hylomorphism is the philosophical theory devised by Aristotle and followed by most of the Scholastics, according to which each body is constituted by two main principles, which are the subject and form. The raw material is that which is formless. Like any material object has a shape, the raw material is the basic substratum of all reality. In the material world, the matter cannot be without shape and form cannot exist without matter.

4 A substance, (that which is called a substance most strictly, primarily, and most of all) is that which is neither said of a subject nor in a subject, e.g., the individual man or the individual horse. The species in which the things primarily called substances are, are called secondary substances, as also are the genera of these species. For example, the individual man belongs in a species, man, and animal is a genus of the species; so these — both man and animal—are called secondary substances. keep the notion of form ${ }^{5}$, we abandon the notion of matter in favor of the notion of movement. According to Aristotle (1999) there are three categories of substances: material substance, formal substance and substance composed of matter and form. In neohylomorphic conception, there are three aspects of relative reality described as:

1) Movement without form.

2) Composed of form and movement.

3) Pure form without movement

The existing being is then composed of form and movement, all attached to its essence. This existing being has an essence that represents its Form, ie, a state which remains motionless. This leads us to make explicit three aspects of relative reality:

1) Existing beings are endowed with a topological unit describable as body unit (composed of form and movement).

2) These beings are determined by an in-self or essential form representing its particular inside synthetic unit (pure Form).

3) Corporeal beings are attached externally concretized as a physical extension as a single movement without Form.

Metaphysical Principle 4: The unfolding of the existing being is effected accordance with a process after the essence. Conversely, the existence is retracted toward the essence as a movement of conversion. The process

(Aristotle, Categories 2a13, trans. J.L. Ackrill). Imperfection is not merely the inadequate instantiation of form by substance. It is not only, as Plato held, that matter is recalcitrant and embodies form only approximately. Form is recalcitrant as well; both are afflicted with the consequences of finitude. It was once believed that perfection and simplicity of form were reflections of the divine, but there were always counter-indications. The Pythagoreans suppressed their discovery of the irrationals. Kepler was forced to sacrifice the beauty of his Platonic solids model of the solar system, as well as the perfection of the circle, in favor of the mathematically inelegant ellipse, which so distressed Kepler that he referred to it as a 'cartful of dung' (Koestler 1959). In our own time, a vision of a perfectly orderly world of form was sought by Whitehead and Russell in their Principia Mathematica (1910), but this vision was decisively undermined by Gödel's theorem, the implications of which are still unfolding. It is commonplace now to note imperfections in the world of form and incapacities of human reason. Game theory, the Arrow Impossibility Theorem, and the theory of computational complexity reveal limits to order and rationality. Cybernetics shows that signal and noise, representation and illusion, are not intrinsically distinguishable. Chaos demonstrates that complexity is implicit in simplicity and severs the connection between determinism and predictability. If the forms are in the heavens, there is strife there as well.

5 Book 9 of Metaphysics (Aristotle, 1999) spells out the consequences of this clarification of form. Form cannot be derivative from or equivalent with material, because material on its own must be mere possibility. It cannot enter the world until it has achieved definiteness by getting to work in some way, and it cannot even be thought except as the possibility of some form. Books 7-9 demonstrate that materiality is a subordinate way of being. The living body does not bring form into the world; it must receive form to come into the world. Form is primary and casual, and the original source of all being in the sensible world must be traced beyond the sensible world, to that which confers unity on forms themselves. If forms had no integrity of their own, the world and things could not hang together and nothing would be. At the end of Book 9, the question of being has become the question of formal unity, the question, what makes each form one? In the woven texture of the organization of the Metaphysics, what comes next, at the beginning of Book 10, is a lying out of all the ways things may be one. Glue, nails, and rope are of no use for the problem at hand, nor, any longer, are natural shapes and motions, which have been shown to have a derivative sort of unity. All that is left in Aristotle's array of possibilities is the unity of that of which the thinking or the knowing is one. 
incorporates movement to the Form; conversion leaves surviving Form that self constitutes, while synthetic and indivisible unit. It is this unity that confers to existing being, its organizational unit.

This principle refers to one conception initiated by Aristotle, and explicated by Neo-Platonist, especially by Proclus ${ }^{6}$. This suggests, in effect, a hylomorphic conception: "The vehicle of the particular soul descends undergirding the material tunics, and dates back with her eliminating what it is material" (Proclus, ET, par 209, in Dodds, 1963). Considering matters as movement, this aspect becomes intelligible, and is interpreted as the essence-existence dynamic dualism. Being then comes from its Form, and passes the existence incorporating movement (efficient) to Form, where the process (morphogenesis) of being in existence, undivided Form is cleaved by motion, and the being is displayed according to body extension (organized system).

Metaphysical Principle 5: Existence precedes essence $e^{7}$. The essence is ontologically first by regarding existence.

If the essence as prior standing by time to the existence, then, the essence Forms are predetermined ${ }^{8}$. The evolution of beings is carried out according to a predetermined plan, and is simply accidents of the essence. It is also necessary to existence as above according to time, in the same way that Aristotle considered the act as before the power. The essence of being is constituted in the course of existence, and this vision can be defined as metaphysics of existence $^{9}$. This idea is remarkably similar to that emitted by the philosopher Mulla Sadr Shirazi ${ }^{10}$, according to

6 Proclus of Athens $(* 412-485$ C.E.) was the most authoritative philosopher of late antiquity and played a crucial role in the transmission of Platonic philosophy from antiquity to the Middle Ages. For almost fifty years, he was head or 'successor' (diadochos, sc. of Plato) of the Platonic 'Academy' in Athens. Being an exceptionally productive writer, he composed commentaries on Aristotle, Euclid and Plato, systematic treatises in all disciplines of philosophy as it was at that time (metaphysics and theology, physics, astronomy, mathematics, ethics) and exegetical works on traditions of religious wisdom (Orphism and Chaldaean Oracles). Proclus had a lasting influence on the development of the late Neoplatonic schools not only in Athens, but also in Alexandria, where his student Ammonius became the head of the school. In a culture dominated by Christianity, the Neoplatonic philosophers had to defend the superiority of the Hellenic traditions of wisdom. Continuing a movement that was inaugurated by Iamblichus (4th c.) and the charismatic figure of emperor Julian, and following the teaching of Syrianus, Proclus was eager to demonstrate the harmony of the ancient religious revelations (the mythologies of Homer and Hesiod, the Orphic theogonies and the Chaldaean Oracles) and to integrate them in the philosophical tradition of Pythagoras and Plato. Towards this end, his Platonic Theology offers a magisterial summa of pagan Hellenic theology. Probably the best starting point for the study of Proclus' philosophy is the Elements of Theology which provide a systematic introduction into the Neoplatonic metaphysical system.

7 The proposition that existence precedes essence is a central claim of existentialism, which reverses the traditional philosophical view that the essence or nature of a thing is more fundamental and immutable than its existence. To existentialists, human beings-through their consciousness - create their own values and determine a meaning for their life because in the beginning, the human being does not possess any inherent identity or value. By posing the acts that constitute him or her, he or she makes his or her existence more significant. The idea can be found in the works of philosopher Søren Kierkegaard in the 19th century, but was explicitly formulated by philosopher Jean-Paul Sartre in the 20th century.

8 In the same way as are the ideas for Plato.

9 In opposition to the metaphysics of essences, as in the case of Avicenna.

10 Sadr al-Din al-Shirazi (Mulla Sadra) is perhaps the single most

important and influential philosopher in the Muslim world in the last four which every essence is variable and determined by the degree in the act of existing (Rahman, 1975). In other words, the being must exist and involved with other beings, existing as in-Form its essence. Then, the Form of the essence depends on the multiple forms acquired in the past of existence (ontogenetic point of view), or during the course of the past existences (phylogenetic viewpoint). Meanwhile, the Form of essence is ontologically first.

\section{The Whole and The Parts}

The first fundamental question concerns the relationship between the whole and the parts, more precisely, the evidencing of mechanisms or principles involved in the functioning of a whole constructed from components, which evolve with a certain degree of autonomy, but in mutual concertation. It is a problem of ontological type. The second fundamental question is referred to emergency properties related to the association of a number of parts. In effect, the whole is built up from components that are self-organizing and has emergent properties that cannot be observed when the components are separated, or the coherence of the system is altered. The questions arising from the empirical-rational science and science of the systems need an "epistemological reframing" and the introduction of a new paradigm instituting the development of "science of being." This "science of being" must have as exact the rational representations, born of objective facts, but must considering that the meaning or Truth of being cannot be located more than out of rational representations, must be restored and the essential foundations of beings, returning to reintroduce metaphysical perspectives of the past, formulating them from modern conceptions.

To understand the relationship between the whole and the parts, we refer to the "whole structure" of being, as a system component. This component is provided with an identity, an Essential Form. Moreover, this same component is provided with a "Non-identity", ie, formal and essential determinations for what he is not. However, these determinations have significance because they are not registered as causality, but are linked to the existence of this component within a whole. Non-identity is resulting from past interactions of this component with other components in the bosom of system. Accordingly, we propose that each component contains, following an essential/intensive mode, the whole Form, that distinguishes it from the Form of the component on the

hundred years. The author of over forty works; he was the culminating figure of the major revival of philosophy in Iran in the sixteenth and seventeenth centuries. Devoting himself almost exclusively to metaphysics, he constructed a critical philosophy which brought together Peripatetic, Illuminationist and Gnostic philosophy along with Shi'ite theology within the compass of what he termed a 'metaphilosophy', the source of which lay in the Islamic revelation and the mystical experience of reality as existence. Mulla Sadra's metaphilosophy was based on existence as the sole constituent of reality, and rejected any role for quiddities or essences in the external world. Existence was for him at once a single unity and an internally articulated dynamic process, the unique source of both unity and diversity. From this fundamental starting point, Mulla Sadra was able to find original solutions to many of the logical, metaphysical and theological difficulties which he had inherited from his predecessors. His major philosophical work is the Asfar (The Four Journeys), which runs to nine volumes in the present printed edition and is a complete presentation of his philosophical ideas. 
approach as idea of the whole. Thus, suggesting that a system of fragmented reality (natural system) is deployed in existence from its essence is admitted that each component is displayed according to its determinations of form in the essence, their Form. However, the Form of each component is essentially related to the idea of the whole. The unfolding of a component is effected by Form, but also according to the Idea. In other words, the idea intervenes while modulating at the level of Form ${ }^{11}$, and makes each component possesses a behavior that is determined by the Idea. An observer subject $S$ finds in this way, that the system is organized. But the deeper reason maintains that the organization is not on the existence. The organized system is a demonstration in the existence, determined by the essence or the Idea. Heidegger (1972) says that being (in the sense of essence) is the Relation, and this appears along the inside relation Form/Idea, while existence is the domain of the interactions between components.

Each part works according to the law of the whole, because it contains the essential level, the inner relationship between itself and the whole. Hegel in his logic of the concept (1969) proposes that the Idea performs the unity of Concept and Reality. Let us admit that the Concept (which is a Form) is related to a component, the Idea is related to the whole, and that Reality is seen as outside and is described as a set of objective quantities that are deployed and propagated in existence in the bosom of system. Each component then receives information from the outside, but is coupled to the other components and integrates information to essential level, and recompose quickly to determine its Concept, latter being in relation to the Idea. The deployment of each component from its Concept is made in relation to the whole, ie, depending on the formal and essential determinations of the Idea, and in function of external interactions from existence. In other words, each component is formed along a spectrum of dynamic states contained in the essence. By this spectrum does not display at any given time, only one of these states, and more precisely, state that: a) depends on the information arising by coupling with the other components and b) unfolds according to the Idea and ordering these states and that are determined ${ }^{12}$. Changing the information with the outside, the component selects/reduces its spectrum of states. Objective information is propagated into the component and the reduction is operated at the essential level (selection of a scheme). Then is occurred an unfolding outwards, which depends on the inner Idea and external interactions. In each spatiotemporal point of the system, at the level of each component, is selected a scheme. The set of these schemes constitutes at level of each component, which determines the space and time in existence, while the essential core is not describable in terms of space and time.

The relationship between the whole and the parts is inscribed, on the other hand, in a holographic perspective, keeping the spirit of that holography is not a model, but a metaphor intended to account for the distribution of

11 Indeed, it is a quantum modulator, changing the own state of the component, and not a continuous modulator.

12 In quantum systems, these states are not ordered by the resulting indeterminacy. information within a system. In other words, information is underdetermined (in essence, the Idea) and each component contains the information on the whole. The substance appears as a dynamic hologram, ie, as a metaphysical supercomputer ${ }^{13}$ which determines the dynamics of every component, therefore the conditions at the limits, that is, the relationship of the dynamics with the other dynamic, constituting field interactions.

If the relationship between the whole and the parts is an ontological problem, understanding the emergent properties related to self-organization, is a problem of ontogenetic type. If the ontological aspect can be said metaphorically "everything is in everything", of ontogenetic aspect we can say "everything becomes everything." Self-organization is linked to the becoming, and presupposes a previous unorganized state, according to time, to organized state. Let us assume that an unorganized state is formed as a set of components, evaluating everyone according to his own Form, in absence of the Idea. During the existence, these components interact and acquire information that makes up the essential level ${ }^{14}$. Self-organization intervenes in a moment of existence, when sufficiently, formal determinations are contained within each component, and when one is crossed, the Idea is constituted within, and the system is tilted, changes its essence, becomes an organized and acquires all the emergent properties determined by the Idea, which individualize the system (entelechy). Self-organization can then be said twice:

1) On one hand, the metaphysical calculator determines the form of the whole, ie the solution of a differential where each component calculates its shape considering the limits. Form is related to the idea. Form is inserted within a determination that includes this Form. Then an inner transformation occurs, describable as a transfiguration: Form is included in a Form/Idea which transcends. It can be considered that the system organizes itself as a conversion to his Idea, which depends on all components.

2) Moreover, a system comes from its essence. Thus, the emergence of new properties is as a result of the incarnation of the Idea through all its components.

According to Greek, Jews and Muslims Neoplatonists ${ }^{15}$, the Universal Essence contains a virtual title, all Forms and Ideas, and "radiates" these ideas over existing beings. Also, an emergent property is the result of a donation of the Idea after of the Essence. Meanwhile, the idea and are not pre-irradiated, and depends on the past interactions between components, according to the metaphysics of existence placed above. Indeed, according to Mulla Sadr Shirazi (Rahman, 1975), the relationship between the essence and the existence is unification and no coupling. The Idea of the system is not preestablished that comes to

13 We note that this supercomputer is not a machine. It works in a particular domain, outside of space-time, according to a mode that is definable as the simultaneity.

14 The new components also appear, but are not in the first accident, hazards of existence.

15 Neoplatonic tradition, created by Plotinus and his successors and filtered through Islamic sources, began to affect Jewish philosophy. The Platonic "forms" were identified with the creative thoughts of God, and God was defined as the Good, the First Principle, and "The One," i.e., as absolutely single and self-sufficient. From this ultimate One, the intelligible world of ideas and the lower forms of being is descended or emanated down to the material world. 
superinduce the existence of the parties. The Idea is emerging on one face, and synthetically unifies (selfconstitutes, entelechy) on the other face. The Idea of the whole is transcendent given by relation to Form of the component in the sense of inclusion, but it is not transcendent in the sense of external reality as the Platonic Idea. Anyway, if the Idea emerges, has in itself the principle that produces its emergency, and establishes the existence as an act. Real idea is therefore efficient and inseparable from the act of existing.

Both the early Jewish philosophers and the medieval Kabbalists were acquainted with and influenced by Platonic and Neoplatonic sources. However, while the medieval philosophers were much more systematic in their borrowing from Neoplatonic sources, especially via their transformations and transmissions from Arabic sources and also but more rarely from Christian sources, the Kabbalists were more sporadic and fragmentary in their appropriation of Neoplatonism. Though the emergence of Kabbalah it has often been described by scholars as the synthesis of Neoplatonism and Gnosticism. The major medieval Neoplatonic Jewish thinker was Shlomo Ibn Gabirol, whose doctrines are found in his Mekor.Hayyim. He stressed that the goal of human existence is the conjunction of the human soul with the supernal world through knowledge and action, specifically intellectual and ethical purification. Ibn Gabirol (Pessin, 20139 argued that the study of philosophy offers liberation from death and conjunction with the source of life. In his Fountain of Life Ibn Gabirol decided to use a classical form of mystical instruction - a dialogue between a master and a pupil of mystics. For this purpose a master, having used the "regulae dialecticae artis", explains to his pupil the key entities of the order of being. These are Essentia prima, Voluntas, and materia et forma. Three different sciences are consistent to them: the science of the First Essence, science of Will and science of matter and form (Goodman, 1992).

The human cannot come to know what Ibn Gabirol labels the "First Essence" because it transcends everything and is incommensurable with the intellect. Material substances come from simple substances which derive from universal matter and form, an emanation of Divine Will. The first principle is the First Essence, Deity, beyond any characterization or comprehension. That it is is shown by the activity of Divine Will. Nevertheless, everything outside the utterly unknowable First Essence is both spiritual and material. Rational soul, an emanation of the first compound of universal matter and form, Intellect, is connected to vegetative soul, the product of the lowest simple substance, Nature, the animating spirit. "The form of the intellect includes all the forms, and they are contained in it", and so the soul is potentially omniscient. Forms alone are knowable, for matter is inherently unintelligible. Involvement with matter can only awaken the soul to its own potentials through discerning the forms imperfectly embodied in it. Above knowledge of form and matter, however, is the wholly transcendental knowledge of Divine Will, which is identical with Divine Wisdom and the Logos. Considered by itself, Will is Divine Essence, infinite in essence though finite in action. The true knowledge that frees the soul to soar to its source is knowledge of the Will. The animating soul in man, when it disciplines the lower soul through aspiration towards the higher soul, manifests the Divine Will. Ethics is thus the initial knowledge of the Will that opens the way to philosophy, which is the science of the Divine Will in actu, freeing the soul to return to That which is above even Will, Absolute Deity, the ever-hidden Source of creation.

In conclusion, self-organization is defined from the dual role of the real, essence-existence, conversion of existence towards essence, process of essence into existence. A more leisurely examination of The Elements of Theology of Proclus (Dodds, 1963) shows that most of the questions on the self-organization of systems that had been put, particularly autopoiesis, which is described according Proclus from the self-constituting essence, which enables to the being becoming in itself, or in other terms, a being is self-constituted from the Idea which is intellective by herself. The self-constituents are essentially timeless, religated to Eternity, not generable and not corruptible (Proclus, par. 45, 46), and out of the space as a single indivisible unit (par. 47). In other words, systems evolve because "retard" on Eternity, and on the other hand, the existence cannot catch Eternity. Achilles cannot reach the Turtle.

\section{Systems Metaphysics and Religion: A Vision from Lurianic Kabbalah}

The systems theory literature often touches upon religious themes. Deutsch (1966) speaks eloquently of 'faith,' 'love,' and 'spirit' within the framework of cybernetic ideas. For Deutsch, religious commitment requires a kind of closeness but responsiveness to the present requires openness; having a harmonious balance between the two is perhaps 'grace.' Beyond metanoia, individual spiritual work, there is also tikkun, redeeming social action in the world, and many systems ideas are relevant to such action. For example, Boulding's work on conflict and cooperation (1962) and Axelrod's The Evolution of Cooperation (1984) show how gametheoretic ideas bear significantly on moral issues and bridge the divide between fact and value.

Systems metaphysics has implications for the sciencereligion dialog:

1) It offers a 'secular theodicy'.

2) It suggests grounds for dialog beyond the usual ideas drawn from physics.

3) It points to the quasi-scientific character of some religious practice.

Systems theory offers an ontology of problems that is a 'theodicy,' but a secular one. Traditionally, theodicy is the reconciling of divine justice and divine power with the reality of evil, the word 'evil' being used not narrowly as an epithet for wrongful human action ('moral evil'), but broadly to include suffering, decay, imperfection, and death ('natural evil'). It is one of the major attractions of a scientific metaphysics that it offers an account of the origins and nature of evil, cast in general terms and linked to scientific understanding.

In reductionist metaphysics, a theodicy is impossible. The problem of evil is divided into smaller unconnected problems, and at the level of elementary particles, it disappears. Evil is not a well-posed problem in physics and from its fundamental point of view is illusion. The systems view "saves the phenomena" and provides a 
general explanation of evil, i.e., of precariousness, dysfunction, and suffering. Central to this view is the recognition that constraint is a property of the cosmos on all levels.

Theodicy system implies the need of each tradition to face its errors and distortions. No religion is truly universal: each is a mixture of the universal and the unique, and suffers the contradictions that this entails; and each is incomplete. Every uniqueness needs other types of uniqueness - the realm of the sacred is an ecosystem, not a single species - and so "religious pluralism is the will of God” (Heschel 1996). All religions navigate clumsily the conflicting demands of variety and constraint, openness and closeness, rigidity and flexibility, centralization and decentralization. All encompass more than what can be consistently organized, and so all are afflicted by contradiction. All were fixed in some deep way, for good and bad, by their origins. All, in some places at some times, turned into their opposites. The acceptance of the fact of imperfection and the value of pluralism are bitter pills for any tradition to swallow, but this acceptance is crucial to rectify tradition and ease relations between religious civilizations. The contrary belief -in the perfection of tradition or of the central figures of tradition-is a form of idolatry. That imperfection and fallibility must be accepted is a central spiritual lesson of modernity and science.

Constraint is opposed by variety, which is not inherently different from disorder, which is another source of imperfection. So, all systems are subject to the dual and conflicting imperatives of constraint and variety, order and disorder. While it is possible to reconcile these imperatives, each of which in isolation causes evil, reconciliation cannot be guaranteed. A systems theodicy declares the universality - really, ubiquity — of this and many other tensions within systems: incompleteness vs. inconsistency, rigidity vs. flexibility, openness vs. closeness, autonomy vs. interdependence, etc., yet does not assert the impossibility of balancing these contrary tendencies and needs. It locates imperfection in the very structure of existence, but it does not preclude it being ameliorated-at least temporarily and locally. If a systems theodicy provides a 'defense of God' by explaining evil and suffering as inevitable components in the natural order, it also provides a 'defense of Man' against the charge, made by western and eastern religious doctrines, that evil and suffering is fundamentally of human origin, due to action or ignorance. This accusation blames the victim. Although some victims are blameworthy and even victims have responsibilities, what original sin there is in humanity only exemplifies the more general sin of origin that is common to all being, the imperfection that afflicts all creation that has its basic source in finitude. 'Sin'-in Hebrew, 'missing the mark' - always comes with origin, i.e., with existence, reflecting the necessary incompleteness and inconsistency of all things. To give a more balanced view, though, finitude is also original virtue, a manifestation of the good that also blesses existence.

Evils have not one but many metaphysical essences, so what is really gained by a metaphysical account over an ethicist's newspaper column or a radical's manifesto? Two answers can be given to this question:
1) Essences are deeper (higher in the 'upwards' metaphor) than appearances, so it behooves us to grasp them.

2) One can in fact give a unitary account of metaphysical evil.

To use the terminology of theodicy, what is being discussed here is 'metaphysical evil.' Leibniz held that metaphysical evil was the basis of both 'natural evil' and 'moral evil' (Neiman, 2002), and the Kabbalist and dialectical position supports this view. More precisely, metaphysical evil encompasses natural evil, and natural evil encompasses moral evil. Metaphysical evil is the most general conception, and includes natural evil as concrete instantiation. Natural evil includes moral evil because humanity is part of the natural order. Both of these inclusions reflect the aspect of isomorphism, i.e., similarity, but under the aspect of difference, specifically emergence, moral evil is also a special case, because humans have unique capacities and thus also responsibilities. Human beings are both part of the natural order and unique, a dual affirmation well articulated by Jonas (1966). Referring moral evil back to natural evil, and natural evil back to metaphysical evil, is, one must admit, a kind of 'reductionism'. It represents, as all reductionisms do, dissatisfaction with multiplicity. But tracing evil back to its metaphysical origins does not allay this dissatisfaction, because multiplicity rules in the heavens as well.

In Kabbalistic metaphysics, constraint is 'severity,' which is intrinsic to-indeed the price of-existence. Scholem (1991) writes in "Sitra Ahra: Good and Evil in the Kabbalah": “... But the act of tsimtsum itself, in which God limits Himself, requires the establishment of the power of Din, which is a force of limitation and restriction. Thus the root of evil ultimately lies in the very nature of Creation itself, in which the harmony of the Infinite cannot, by definition, persist; because of its nature as Creation-i.e., as other than Godhead-an element of imbalance, defectiveness, and darkness must enter into every restricted existence, however sublime it may be. It is precisely the rigorously theistic tendency of Lurianic Kabbalah that requires evil as a factor necessarily inherent in Creation per se, without which Creation would necessarily lose its separate existence and return to being absorbed in the Infinite." It is surely a stretch to give mathematical interpretations to Kabbalist ideas, but, encouraged by Boulding's injunction that systems thinkers should not be afraid to appear ridiculous and by his personal example of boldness, consider the following: tsimtsum, in terms of the set-theoretic definition of constraint, is the necessary diminution of the possible in the actual: there is no order, i.e., coherent existence, without constraint, without the exclusion of possible states. Or, in terms of the system-environment distinction, tsimtsum is incompleteness, the 'constriction' or limitedness of a system within its context. Every system exists within some larger environment. This is to apply Lurianic ideas to individual systems, not to creation as a whole. Lurianic Kabbalah offers such a view for the problem of evil. Related to this view is the quote from Spinoza: metaphysical evil has its ultimate source in incompleteness, in the finitude of every "mode," i.e., system. The quote speaks of the fate of man, but this is to give concrete expression to what is really an abstract 
proposition: every mode is finite-has an environmentand thus is not the adequate cause of its own fate. Spinoza's philosophy-except for his determinism-is systems metaphysics, as Jonas (1965) has noted. Incompleteness, the necessary affliction of wholeness, which manifests in both internal constraint and external limitation, is the most general explanation for evil. The task of perfecting (in Kabbalah, Tikkun) is in the hands of life, and more specifically, human life. Imperfection in the human sphere is partially and provisionally remediable; we can affect and are thus accountable for the quality of our own domain of existence.

\section{Epilogue}

The past has seen the emergence of two types of metaphysics:

1) Dogmatic, which been made of the essence a separate thing, and the existence an accident of essence, where, for example, the dogma of the Fall and Original Sin.

2) Realistic while metaphysics of existence, distinguishing, but not separating the existence of the essential causes.

From the above, we can draw the following conclusions:

1) A productive encounter between modern science and religious tradition would begin the recovery of cultural coherence. It would also open up possibilities of communication between the different religious traditions by providing a neutral scientific background, as it were, for such dialog. Religion will never be reconciled with science if it reflects the perspective only of one tradition. No aspect of science offers greater support for the sciencereligion dialog and the unity of religion than the systems world view that seeks to embrace the whole but does not flinch from the impossibility of doing so. In the recovery of old forms of knowledge eclipsed by science, in the establishment of a new connection between religious and scientific understanding, in the ingathering of traditions and the correction, refinement, and augmentation of the great sacred approximations, theory of systems and systems metaphysics have important contributions to make.

2) Many aspects of the natural order that cause suffering are also corrigible. Though we are not to blame (but merely partake in it), we are still responsible. By accepting this responsibility, we become the mediating factor through which polarities may be integrated and transformed (Usó-Doménech, Nescolarde-Selva, PérezGonzaga and Sabán, 2015). We are charged with the rectification of creation and our actions have metaphysical significance. Tikkun begins at home, with the religious traditions themselves, which are systems of thought and practice in the real world and thus necessarily imperfect. This does not mean that just the followers of the traditions are imperfect; the traditions themselves are flawed. This is plain from any historical or scientific perspective.

\section{References}

[1] Ackrill, J.L. 1988. A New Aristotle Reader. Princeton University Press.

[2] Aristotle. 1999. Metaphysics, Joe Sachs (trans.), Green Lion Press.

[3] Axelrod, R. 1984. The Evolution of Cooperation. New York: Basic Books.

[4] Boulding, K. 1956. General Systems Theory - the Skeleton of Science. Management Science 2, pp. 197-208. Reprinted in Buckley, ed. (1968), Modern Systems Research for the Behavioral Scientist. Chicago: Aldine.

[5] Boulding, K. 1962. Conflict and Defense. New York: Harper and Row.

[6] Deutsch, K. 1966. The Nerves of Government. New York: Free Press.

[7] Dodds, E.R.. 1933, [1963]. The Elements of Theology, Oxford: Clarendon.

[8] Goodman, L.E. (Ed). 1992. Neoplatonism and Jewish Thought. State University of New York. Albany.

[9] Hegel, G.W.F. 1969. Hegel's Science of Logic. Allen \& Unwin, Retrieved 2 January 2012.

[10] Heidegger, M. 1972. On Time and Being. Translated by Joan Stambaugh. Harper \& Row. New York.

[11] Heschel, A. J. 1996. Moral Grandeur and Spiritual Audacity, Susannah Heschel, ed., New York: Farrar, Straus \& Ciroux.

[12] Jonas, H. 1965. Spinoza and the Theory of the Organism. Journal of the History of Philosophy, 3, pp. 43-58. Reprinted in Grene, Marjorie, ed. (1979). Spinoza. A Collection of Critical Essays. Notre Dame: University of Notre Dame Press, pp. 259-278.

[13] Koestler, A. 1959. The Sleepwalkers: A History of Man's Changing Vision of the Universe. London: Penguin.

[14] LeShan, L. and Margenau, H. 1982. Einstein's Space and Van Gogh's Sky. MacMillan Publ. Co. Inc. New York.

[15] Lovejoy, A. O. 1936. The Great Chain of Being: A Study of the History of an Idea. Cambridge: Harvard University Press.

[16] Neiman, S. 2002. Evil in Modern Thought: An Alternative History of Philosophy. Princeton: Princeton University Press.

[17] Nescolarde-Selva, J. and Usó-Doménech, J. 2014 Reality, System and Impure Systems. Foundations of Science. Vol 19, pp 289-396.

[18] Nescolarde-Selva, J. A., Usó-Doménech, J.L. and Gash, H. 2014. A theorical point of view of reality, perception, and language. Complexity. Vol 20 (1), pp 27-37.

[19] Nescolarde-Selva, J., Usó-Doménech, J.L. and Sabán, M.J. 2015. Linguistic knowledge of Reality: a metaphysical impossibility? Foundations of Science. 20 (1). 27-58.

[20] Pessin, S. 2013. Ibn Gabirol's Theology of Desire: Matter and Method in Jewish Medieval Neoplatonism. Cambridge University Press.

[21] Rahman, F. 1975. The Philosophy of Mulla Sadr (Sadr al-Din alShirazi), Albany, NY: State University of New York Press.

[22] Schelling, F.W.J. 2000. The Ages of the World. Translated with and introduction, by Jason M. Wirth. State University of New York Press. New York.

[23] Scholem, G. 1991. On the Mystical Shape of the Godhead. New York: Schocken.

[24] Teilhard De Chardin, P. 1959. The Phenomenon of Man. New York: Harper \& Row.

[25] Usó-Doménech, J.L. and Nescolarde-Selva, J. 2012. Mathematic and semiotic theory of ideological systems. Editorial LAP. Saarbrücken. Germany.

[26] Usó-Doménech, J.L., Nescolarde-Selva, J., Pérez-Gonzaga, S and Sabán, M. 2015. Paraconsistent Multivalued Logic and Coincidentia Oppositorum: Evaluation with Complex Numbers. American Journal of Systems and Software. Vol 3 (1), pp 1-12.

[27] Wheeler, J. Ar. 1994. It from Bit. In At Home in the Universe, by J. A. Wheeler. Woodbury, NY: American Institute of Physics Press: 295-312

[28] Whitehead, A, N. and Russell, B. 1910-1913. Principia Mathematica. Cambridge: Cambridge University Press.

[29] Wolfson, E. 1998. Perspectives on Jewish Thought and Mysticism, edited together with Alfred Ivry and Alan Arkush. Harwood Academic Publishers. 